\title{
Strategies for Repositioning Participation in Adult Education in the Contemporary World
}

\author{
Ugwu, AngelaNkechi*, Oyebamiji, M.A. \\ Department of Adult \& Non-Formal Education Faculty of Education, University of Port Harcourt, Nigeria \\ *Corresponding Author: Ugwu, AngelaNkechi, Department of Adult \& Non-Formal Education Faculty \\ of Education, University of Port Harcourt, Nigeria
}

\begin{abstract}
Most countries of the world especially the developing nations like Nigeria are undergoing rapid changes economically, socially, politically, culturally and technologically. To meet the challenges in the fastchanging world, adult education becomes a vital instrument. In the process of globalisation, all countries are expected to preserve their existence and to develop their competitiveness through knowledge, that is, to cooperate in the development of their respective education systems, a process in which each country reserves the right to respect their own history, culture, education and traditions. Therefore, it is pertinent for any group of people who want to stimulate sustainable societal change to engage in that form of education, adult education in particular which is not for the future, but for now and for immediate use by the productive sector of any nation's economy. Adult education is an integral part of life-long education or learning/knowledge that helps to continuouslyrevitalise the engine room of societal development through adult participation. In lieu' of this, this paper examined strategies that can be used to reposition participation in adult education in the contemporary world.
\end{abstract}

Keywords: Strategies, Reposition, Participation, Adult Education

\section{INTRODUCTION}

Today, the world is facing major challenges due to the quality of education in existence. The current difficult economic climate has highlighted the importance of education as a channel for economic growth. The world is also facing the effects of an ageing population and social exclusion continues to be a serious challenge for all the countries of the world. The problem of low-skilled adults whose future looks increasingly marginal across the globe that will concentrate on knowledge-intensive jobs needs to be tackled. There is also the need to keep up with technological changes and advancement in order keep the world connected. Access to high-quality adult learning plays a decisive role in developing better skills and competences that contribute to employability and the overall competitiveness in the world. It is alsoa fact that learning brings equally important benefits for adults' social inclusion and personal fulfillment. Dixon (2019) noted that the world is facing a learning crisis;and buttressed this point by saying that worldwide, hundreds of millions of children reach young adulthood without even the most basic skills of simple calculation. UNESCO (2009) in Ugwu (2016) stated that adult education is a critical and necessary response to the challenges that confront us. These challenges include economic retardation, health, climate change, social exclusion, political issues, insecurity, illiteracy etc.

Participation in learning helps people to secure a constructive and active role in their local communities and in the society at large. It can help reduce health costs and the incidence of criminality, for instance, while also helping to reduce poverty (Bliss, 2004;McGivney, 2001). Moreover, one cannot underestimate the importance of learning for personal development and wellbeing. Yet, statistics shows that only a small proportion of adults participate in learning, with large variations between countries (Comings, 2003). Even more alarming is the fact that most countries average rate of participation in adult learning has been slowly decreasing since 2005 (Egwu, 2012).

In lieu of the aforementioned, decisive and concerted action is needed to reverse this trend in order to have a reasonable percentage of adult participation in learning by 2020. Consequently, the first challenge that needs to be addressed is to increase participation in adult learning and to make everyone, that is, learners, providers, stakeholders and policy makers to be aware of the benefits of a 
high quality, easily accessible and equitable adult learning system. It is on this basis therefore that this paper discussed strategies that can be used to reposition participation in adult education in the contemporary world and beyond.

\section{Who SHOULd BE InVOLVED In REPOSITIONING PARTICIPATION IN ADULT EdUCATION?}

According to Macleod (2003), the primary target groups to reposition participation in adult education are:

(i). Governments

(ii). Education providers

(iii). Non-Governmental Organizations (NGOs)

(iv). Social partners

\subsection{Governments}

Local governments can execute campaign activities developed at national level or initiate programmes of their own. These may facilitate stakeholders operating at community level to best deliver their activities. It is likely that local governments' capacity to initiate adult learning awareness-raising activities will largely depend on their level of autonomy and access to funding. The positioning they enjoy, however, puts them in a privileged position to interact directly with the adult population, beyond the provision of education services. Local governments represent the closest-to-the citizen public authority and thus have considerable potential capacity to re-direct citizens towards adult learning opportunities. Acting as a gateway to national government policies and funding streams, local governments are also well positioned to communicate and disseminate information to stakeholders within the adult learning community, with the potential of helping the establishment of networks for cooperation. The major goals of governments should be to:

$\rightarrow$ Disseminate research and sectoral policy reports. National governments should ensure that these research outputs successfully reach the actors in the field.

$\rightarrow$ Set-up adult learning objectives and priorities at national level. It is the remit of national governments to determine the status quo of adult learning and its progress, and to establish national goals and priorities, which state and local governments and organizations can then work towards achieving within their geographical areas.

$\rightarrow$ Establish stakeholder cooperation networks. National governments have access to stakeholders across the spectrum of adult education, including education providers, funders, employers, and Non-Governmental Organizations. National governments are therefore ideally situated to encourage cross-sectoral dialogue between stakeholders to achieve more streamlined and efficient provision and funding of adult education.

$\rightarrow$ Conduct evaluation and quality assurance: National governments should conduct regular evaluations on the quality of education being provided at national, state and local levels, and should specifically target education providers in the adult education sector to push for quality improvement.

$\rightarrow$ Promote operational policy changes, particularly in the following:

- Help overcome structural, situational, psychological barriers to access

- Public consultations and open dialogue with stakeholders in the adult education community

- Create National Institutes for Adult Learning (in countries where this does not already exist)

- Incentivize, reward and recognize participation from the private sector

- Give adult learning visibility within other policy areas

- Provide funding for adult learning facilities 
$\rightarrow$ Conduct research on the local needs of the adult population: This will serve as baseline for a call to action at business and civil society level, and will help identify socio-demographic targets, thereby complementing research efforts initiated at national level.

$\rightarrow$ Implement state/local awareness-raising strategies: These will comprise segments of wider nationwide campaigns or locally-initiated programmes. They may include outreach work, mobilization of multipliers for dissemination purposes, provision of one-stop-shop information access points on adult learning, etc.

$\rightarrow$ Facilitate efforts at civil society level: Executing actors may need help in delivering their programmes, providing courses or developing campaign ideas. Improving action in three key identified areas is considered essential:

- Collate and optimize visibility of information on funding opportunities

- Establish networks of cooperation among stakeholders

- Produce pre-packaged information material

$\rightarrow$ Provide opportunities for knowledge sharing with other local actors: This includes evaluation, successful best practice identification, making these practices available.

\subsection{Education Providers}

These represent a key stakeholder in the process of adult education. They have to be convinced of the necessity to provide further education in response to existing demand. It is essential that they base and adapt their educational offers to the needs of learners. It is the responsibility of the providers to give information to the government. Governments need to know what their education systems are missing (Dixon, 2019). Education providers also have to convince adult learners to participate in their programmes in order to achieve a return on their investments. Moreover, both public and private sector providers of learning and training services bring a wealth of experience of direct interaction with learners and potential learners, and should therefore be encouraged to share their experiences in reaching and interacting with other stakeholders. Their goals should be to:

$\rightarrow$ Amplify offer to meet demand and target groups' needs

$\rightarrow$ Communicate to individuals the social benefits of adult learning

$\rightarrow$ Form strategic partnerships with other stakeholders to provide quality education

$\rightarrow$ Cooperate with businesses and NGOs to provide course developers with feedback regarding current skills demand and possible work experience placements

$\rightarrow$ Market educational offer through intermediaries such as national institutes for adult learning, NGOs, as well as community learning champions, learner representatives, outreach workers, support workers, and tutors

$\rightarrow$ Use online tools to raise awareness of and deliver education courses

\subsection{Non-Governmental Organizations (NGOs)}

NGOs have the capacity to complement research gaps in the identification of learners' needs and necessary changes or interventions at structural policy level. The groups they seek to reach out to are thus different in nature and require multiple targeted awareness-raising activities. The remit of intervention of civil society organizations, however, depends on resources available and scope of activities. The goals of NGOs should be to:

$\rightarrow$ Disseminate the needs of learners they work with on a daily basis, and make them known at policy level through lobbying, campaigning, awareness raising, direct actions and working with the media.

$\rightarrow$ Develop and implement campaigns targeting adult learners

$\rightarrow$ Provide training and mentoring courses and relevant certificates for adult learning teaching staff with a view to initiate exchange of qualified training and mentoring personnel on local and state levels. 
$\rightarrow$ Create strategic coalitions with other stakeholders in order to have positive environment on advocacy for adult learning. These coalitions need not necessarily be only in the adult education sphere, but should also target associations for active and healthy ageing, media literacy organizations, publishers, etc.

\subsection{Social Partner}

These are considered a key stakeholder group as they interact directly with target groups to educate them on the benefits and importance of adult education. Acting as a gateway to employment and the provision of professional training, social partners provide and/or receive funding and they help disseminate awareness raising tools provided by other stakeholders. Operating on a community level, they use face-to-face communications, develop print material, create networking events or develop training for employees. Their major goals should be to:

$\rightarrow$ Disseminate tools produced by other stakeholders: The objective of this activity is to contribute to the promotion of courses provided by adult education facilities and to the exchange of campaign ideas, ads, case studies or budgetary information.

$\rightarrow$ Interact with target groups to educate them on the benefits and importance of adult education: Social partners such as trade unions should ensure that their members promote the benefits of adult education to their employer organizations, and convince these employers to make adult learning courses available.

$\rightarrow$ Create networking events: This aims at building strategic partnerships with social partners and public and private education providers to better disseminate information on available courses and to gather information on current skills requirements. Networking events will also mobilize multipliers to disseminate information about the added value of adult education and encourage education providers to exchange best practice.

$\rightarrow$ Develop work-based learning and training for employees: This activity aims at enabling employees to learn and develop new skills that can further their professional lives and contribute to the overall success of an organization. Education providers should be integrated in the development of training courses to provide best practice and knowledge.

\section{How Can Participation In Adult Education Be Repositioned?}

Strategically, participation in adult education can be repositioned through the following:

\subsection{Set Objectives}

$\rightarrow$ Develop a comprehensive campaign plan: Every campaign initiative should begin with a clear plan with clearly pre-defined 'SMART' objectives. In addition, ensure that objectives are constantly evaluated against their results, and updated to keep them 'SMART'. Objectives at all times have to be realistic and achievable, while taking into account the existing situation.

$\rightarrow$ Align goals with wider agenda: While setting up campaign objectives and goals, if possible, they should be linked with goals common to other national stakeholders.

$\rightarrow$ Develop a corporate identity: A campaign plan should be used to build a specific identity for the promoted programme (e.g. using a slogan or logo) and thus ensure consistency of dissemination activities and easy recognition on the part of the target group.

\subsection{Identify Target Groups}

$\rightarrow$ Thoroughly research specific target groups: Target groups are differentiated in their attitudes, disposition and approach towards adult learning. This diversity can be found even within the same demographic or socio-economic groups. It is therefore important to thoroughly research the specific target group that would be participating in the activity, and ensure that the approach to each group is varied to reflect their needs and to encourage their participation. It is also important to consider the preferences of each target group in terms of information delivery. Only in-depth research can reveal how specific target groups wish to receive information.

$\rightarrow$ Take account of polarity in views: Potential learners are not always disposed to join an educational course or activity. While they can often be convinced through targeted campaigns, sometimes 
their views are too polarised to change. It is therefore pertinent not to force them into learning. Constant reminders could cause them to further distance themselves from education.

$\rightarrow$ Do not only target learners: Whilst developing a campaign, ensure that target groups include disseminators/multipliers, influencers (third party endorsers) as well as adult learners. These groups (such as the media) should be treated as a separate target group, and activities and messages should be customised for them (Hillage\& Aston, 2001). Their inclusion will ensure that the campaign reaches a wider audience.

$\rightarrow$ Develop activities for marginalised groups: The education needs of groups that are at risk of social exclusion have to be addressed in a different manner than others. While developing an adult learning strategy targeted towards these marginalised groups, the focus should be on bringing them into the fold of mainstream society, before involving them in further education.

$\rightarrow$ Involve policy makers: Involving policy makers through the design and development of a programme ensures that they become active stakeholders, rather than passive listeners.

\subsection{Identify Tools and Channels to Use}

$\rightarrow$ Use accessible activities: There are activities that encourage adult learners to acquire new skills, such as dance and cooking. These activities can be used as a learning experience or as a means to 'hook' learners into future activities.

$\rightarrow$ Encourage peer to peer learning: Encouraging learners to be trained and teach other learners provides numerous benefits such as:

- providing learners with the motivation to complete the course in order to become teachers and thereby receive compensation

- since the teachers were once learners themselves, they are aware of the obstacles faced by learners, and can customize teaching to suit learners' needs.

$\rightarrow$ Develop toolkits: It is important to provide stakeholders who are developing programmes and campaigns with more than just other examples of best practice. Guidance needs to be more structured, specific, and process-oriented in the form of operational tools to develop, implement and evaluate campaign programmes. These include communication plan guidelines, research tools, campaign ads, strategy ideas, budgeting tutorials and other operational tools.

$\rightarrow$ Show real learning situations: While promoting an activity, it is useful to show potential learners an actual learning situation, so they can understand the type of experience they would have should they return to learning. This can be very important to 'sell' formal education; often, potential learners are disinclined to re-enter education due to the negative associations they have with education in a classroom setting.

$\rightarrow$ Allow sampling of activities: During the development of an activity, build in processes that allow target audience to 'sample' the activity, try participating, and if they desire, continue. If they should decide not to continue, the activity should still be open to them for future participation. By knowing up front that they can leave should the activity not be suitable, potential learners are further encouraged to try the activity, since they have nothing to lose.

$\rightarrow$ Use intergenerational learning: Learning situations which encourage parents to interact with their children can be successful, as parents are more likely to be engaged when they are helping their children to learn. Often, parents do not have an interest in active learning, and will participate in activities simply because those of their children require their involvement. However, this should be viewed as a learning end to itself: even if parents are not participating in adult learning, their 'shared learning' with their children should be encouraged. This brings them into the fold of learning (in any form), and could act as a catalyst to future education activities.

$\rightarrow$ Use online media: The use of online tools is important as the internet is a primary information source for today's society. Online tools increase the geographical scope of an activity and thereby raise participant numbers. They also demonstrate the versatility of an activity and facilitate interaction between learners, which ultimately supports the sustainability of the activity. 
However, the development and implementation of an online media campaign requires the same time and human resource investment as a campaign using regular media. It is thus important to ensure that any online campaign is established with a long term view, and that sufficient resources are dedicated to its execution.

$\rightarrow$ Engage educational professionals: Whilst developing activities and promotional campaigns, aim to involve education professionals from the field of adult education. They have already worked with the target audience and are familiar with their needs and requirements, and therefore more likely to develop activities that would best suit them.

$\rightarrow$ Push stakeholders to take up leadership roles: Stakeholders should not simply be engaged as executing actors of a campaign, but directly empowered to act as active advocates of the cause. This helps them drive their target groups independent of the campaign, thereby favouring greater sustainability of efforts undertaken.

$\rightarrow$ Use role models: In the publicity of adult education, it is important to use role models who are appealing to learners. Similarly, by using actual learners as role models, the campaign becomes more accessibly, and real for potential learners. This is specifically pertinent if the potential learners are from varied backgrounds: listening to those similar to themselves share their positive experience, they could be encouraged to follow the path of the role models.

$\rightarrow$ Use teachers to promote adult education in libraries, community centres, etc.: Local level communication campaigns should leverage the potential influence played by teachers in promoting learning opportunities. Empowering teachers to directly reach out to learners and act as ambassadors in community organizations, libraries and cultural centres gives credibility to learning programmes and offers a first-hand opportunity for them to understand how the educational offer should be tailored to the real needs of learners.

\subsection{Identify Sources of Funding}

$\rightarrow$ Identify multiple sources of funding: In addition to traditional sources of funding such as the governments, organisations should try to solicit sponsorships from other sector specific organisations with a vested interest in educating adults in their particular fields. If the sponsor is convinced of the value in investing, they are also likely to highlight their participation, thereby assuring more promotion for the activity.

$\rightarrow$ Pool resources to reduce costs: The pooling of resources by partner organizations optimises campaign and programme outcomes, not only in terms of promotion and awareness raising of each other, but also in terms of reduced costs, avoiding the repetition of efforts, and reducing the proliferation of disjointed initiatives with limited potential of impact.

\subsection{Develop Campaign Messages}

$\rightarrow$ Aim to build the confidence of learners: By developing campaigns that aim to build the target group's confidence in their ability to learn, it sends the message that society cares about including them in all social aspects, and therefore increases their self worth and confidence.

$\rightarrow$ Encourage learners to stay in learning: Activities developed should encourage a learner's educational journey.

$\rightarrow$ Highlight the variety of adult education: Adult learning is multifaceted and can take place in different forms, in terms of course content, structure, and format. Emphasis should be placed on communicating to potential learners the variety of options available to them. They should be made aware that adult education opportunities are available in different formats and options, depending on lifestyle and time.

\subsection{Develop Campaign}

$\rightarrow$ Create evidence-based strategies: Any campaign strategy or programme should be based on evidence, and should address a specific need of the target audience. This requires upfront research and proper understanding of the environment and its target groups.

$\rightarrow$ Centralise campaign but decentralize implementation: Ensure that the campaign has a single visual identity and centralised plan for the rollout, but assign responsibility for implementation to 
state/local level according to a decentralized structure. Using such an approach allows enough flexibility to address local level challenges and adapt the delivery of promotional tools to each specific context, whilst ensuring national consistency.

$\rightarrow$ Require commitment from learners: Once learners have decided that they want to participate in a programme, it is important to ensure that they provide a commitment to the completion of the activity. A time commitment ensures that the programme can bring about the expected learning outcome, and be of benefit to learners.

$\rightarrow$ Reward achievements: The benefits of rewarding learners' achievements through prizes go beyond providing incentives to potential learners to re-enter education. It also highlights to policy makers the progress made in the field of adult education, and underlines future steps to be taken, where their support would be needed.

$\rightarrow$ Provide support during and after activity: It is important to provide an immediate call to action within a programme or campaign that has a tangible benefit to the potential participant. This call to action should be supported by advice on the benefits available to the participant, including if possible after the programme has closed. Potential learners could get discouraged if they do not have an easy way to see what their options are.

\subsection{Promote Campaign}

$\rightarrow$ Do not limit innovation to only the activities themselves: There is an emphasis put on developing innovative new interventions to get potential learners involved in education. However, this search for innovation should not be limited only to the initiatives. If a common activity is promoted in an innovative way, it will also ensure uptake. This approach helps reduce the risk of adult learning becoming rhetorical and abstract.

$\rightarrow$ Highlight soft skills: Adult learning often leads to benefits such as heightened confidence levels of learners and improved social integration. It is important to measure the progress of learners' soft skills through detailed assessment questionnaire, as this helps in the development of future programmes that allow for all round learning. Highlighting these benefits could also attract adult learners who may be interested in a non-formal environment in which they could improve their soft skills.

$\rightarrow$ Involve learners themselves in promotional activities: Campaigns that involve existing learners in promotional activities would allow potential learners to get an idea directly as to what the learning experience is like. In addition, when potential learners share firsthand what their learning experience is, the activity becomes more accessible for them.

$\rightarrow$ Build lasting relationships with the media: Cultivating lasting relationships with media would benefit successful advocacy on adult learning issues. This would require learning what the journalist covers, communicating to them the value of the pitch, and providing relevant materials when appropriate, over an extended period of time. Media coverage is one of the best ways to gain the attention of decision makers, and can also be used to publicize local level activities.

\subsection{Monitor and Evaluate Campaign}

$\rightarrow$ Monitor national research: Monitoring existing national research enables two activities: First, it helps organizations identify existing needs of the population and develop activities to target them, without having to spend any resources itself in conducting primary research; and secondly, it allows organizations to identify gaps and commission further research as required.

$\rightarrow$ Pilot programmes and use pre-testing: Before launching a campaign strategy or programme, it is important to identify the right tools, channels and messaging. In order to ensure that they are optimal for the target audience, it is necessary to pre-test and adapt them according to feedback. Moreover, if permissible by logistical and budgetary constraints, before the full roll-out of an activity, it should be piloted amongst a smaller group of the target audience. The use of consultations with relevant stakeholders can ensure that divergences in expectations are minimized, the programme answers the needs and preferences of target groups, and any aspects of the programme that do not work can be amended before it is launched. 
$\rightarrow$ Support external evaluation with internal monitoring: This allows for the identification of emerging best practice as well as the targeting of specific recommendations to actors in charge of implementing the programme in its participating regions.

\section{CONClusion}

This paper has established that participation can only be sustained in adult education if the system provides knowledge and skills corresponding to the needs of potential users, or demands of an individual, the labour market, or the broader community. The paper also revealed that repositioning participation in adult education requires a collaborative action or synergy among all stakeholders. Also, the paper presented strategies to raise awareness on adult education and explores how to make adult education more popular and more accessible for target groups. Furthermore, the paper suggested that all stakeholders in adult education should adopt the proposed strategies for future activities and to advocate for adult education that is of high quality, attractive, and within reach of all citizens.

\section{REFERENCES}

[1] Bliss, J. (2004). Adult learning and adult education: A provincial/territorial survey of current policies and practices. Council of Minister of Education of Canada, 27-35.

[2] Comings, J. P. (2003). Establishing an evidence based adult learning system. Cambridge: National Centre for the Study of Adult Learning and Literacy.

[3] Dixon, A. (2019). The education crisis: Being in school is not the same as learning. www.worldbank.org

[4] Egwu, S.O. (2012). Adult education as a catalyst for developing human resources in Nigeria. Paper presented at the 2012 Annual National Conference of Faculty of Education, Enugu State University of Science and Technology (ESUT) Nigeria held on 22nd to 26th October, 2012. Unpublished

[5] Macleod, D. (2003). Widening adult participation: A review of research and development. London: Learning and Skills Development Agency. http://www.lsda.org.uk/files/PDF/1513.pdf

[6] McGivney, V. (2001). Fixing or changing the pattern? Reflections on adult learning. Leicester: NIACE.

[7] Hillage, J. \& Aston, J. (2001). Attracting new learners: A literature review. London: Learning and Skills Development Agency (LSDA).

[8] Ugwu, A. N. (2016). Adult education and economic development. In J.M. Ebong\& J. D. Asodike (eds). Economics of education trends in Nigeria. Port Harcourt: Eagle Lithograph Publishers. 190-201.

Citation: Ugwu, AngelaNkechi, Oyebamiji, M.A. "Strategies for Repositioning Participation in Adult Education in the Contemporary World" International Journal of Humanities Social Sciences and Education (IJHSSE), vol 8, no. 2, 2021, pp. 142-149. doi: https://doi.org/10.20431/2349-0381.0802013.

Copyright: () 2021 Authors. This is an open-access article distributed under the terms of the Creative Commons Attribution License, which permits unrestricted use, distribution, and reproduction in any medium, provided the original author and source are credited. 